\title{
Application of a new parameter in the 6-minute walk test for manifold analysis of exercise capacity in patients with COPD
}

This article was published in the following Dove Press journal:

International Journal of COPD

3 November 2014

Number of times this article has been viewed

\author{
Naoki ljiri' \\ Hiroshi Kanazawa' \\ Takahiro Yoshikawa ${ }^{2}$ \\ Kazuto Hirata' \\ 'Department of Respiratory Medicine \\ ${ }^{2}$ Department of Sports Medicine, \\ Graduate School of Medicine, Osaka \\ City University, Osaka, Japan
}

Background: New parameters in the 6-minute walk test (6MWT) are required for comprehensive analysis of exercise capacity in patients with chronic obstructive pulmonary disease (COPD). The aim of the present study was to apply a novel index, the desaturation distance ratio (DDR), to clinical research on COPD as an estimate of exercise capacity and to examine whether DDR is a potential parameter for manifold analysis of exercise capacity in patients with COPD.

Methods: A total of 41 patients with COPD (median age [interquartile range] $=75$ [68-79] years; and body mass index $[\mathrm{BMI}]=22.3[19.4-23.8] \mathrm{kg} / \mathrm{m}^{2}$ ) participated in the study. The 6MWT was performed along with anthropometric measurements and a pulmonary function test. The "desaturation area" was measured as the total area above the curve created using peripheral oxygen saturation $\left(\mathrm{SpO}_{2}\right)$ values observed at each minute during the 6MWT. Then the DDR was calculated as the ratio of the desaturation area to the 6-minute walk distance (6MWD).

Results: The 6MWD was $370(328-445) \mathrm{m}$, and the decline in $\mathrm{SpO}_{2}$ values $\left(\Delta \mathrm{SpO}_{2}\right)$ was $-5.0 \%(-8.0 \%$ to $-1.5 \%)$. The DDR correlated modestly with baseline pulmonary function in patients with COPD (forced expiratory volume in 1 second [\% of predicted value]: $r=-0.658$, $P<0.001$; and diffusing capacity of the lung for carbon monoxide $\left[\mathrm{DL}_{\mathrm{CO}}\right]: r=-0.470, P=0.002$ ), comparable with the findings of the 6MWD. The DDR correlated well with $\Delta \mathrm{SpO}_{2}(r=-0.656$, $P<0.001)$ and with the increase in subjective sense of dyspnea during the 6MWT, as assessed by Borg scale scores ( $\triangle$ Borg) $(r=0.486, P=0.001)$, in contrast with the $6 \mathrm{MWD}$, which was not significantly correlated with $\Delta \mathrm{SpO}_{2}$ and $\Delta$ Borg scale scores.

Conclusion: The DDR is more informative for manifold analysis of exercise capacity associated with oxygen desaturation and subsequent sense of dyspnea by exercise in patients with COPD. Keywords: chronic obstructive pulmonary disease, DDR, six-minute walk distance, 6MWD

\section{Introduction}

Chronic obstructive pulmonary disease (COPD) is recognized as a serious global health burden with an increasing trend of incidence, estimated to represent the third most common cause of death worldwide by $2020 .^{1}$ Patients with COPD experience chronic cough, sputum production, and dyspnea at rest and during daily activities. ${ }^{2,3}$ As the disease progresses, dyspnea on exertion limits physical activity and is associated with higher mortality. ${ }^{4}$ In addition, reductions in physical activity have been observed even in mild cases. ${ }^{5}$ Accordingly, an assessment of the limitations of physical activity is important for clinical management of patients with COPD.

The 6-minute walk test (6MWT) has classically been used in clinical settings to evaluate exercise capacity at submaximal exercise levels and to assess the effects of treatment in individuals with a variety of cardiovascular and pulmonary
Correspondence: Hiroshi Kanazawa Department of Respiratory Medicine, Graduate School of Medicine, Osaka City University, I-4-3 Asahi-machi, Abeno-ku, Osaka 545-8585, Japan

Tel +8I 666453916

Fax +8I 666466067

Email kanazawa-h@med.osaka-cu.ac.jp 
diseases, including COPD. ${ }^{6-9}$ The test is easy to administer, better tolerated than some other tests, and is reflective of physical activities. In particular, the 6-minute walk distance (6MWD) has been widely applied as a representative parameter in the 6MWT, in patients with COPD. As described in the official statements of 6MWT guideline, ${ }^{10}$ the test was originally designed to assess the integrated responses of the body systems involved during exercise, including the pulmonary and cardiovascular systems, neuromuscular units, and muscle metabolism. However, it is unclear whether existing parameters, like the 6MWD, are suitable for analysis of the functional contribution of individual body systems during exercise. Considering that COPD has recently been characterized by multiple phenotypes of the respiratory, cardiovascular, and muscular systems, it is likely that all these systems play roles in the pathogenesis of reduced exercise capacity in patients with COPD. ${ }^{11}$ Therefore, new parameters in the 6MWT are now required for manifold analysis of exercise capacity in patients with COPD.

A previous study proposed a novel index, referred to as the desaturation distance ratio (DDR), calculated by using the $6 \mathrm{MWD}$ and continuous peripheral oxygen saturation $\left(\mathrm{SpO}_{2}\right)$ values in the $6 \mathrm{MWT} .^{12}$ The DDR was originally designed to comprehensively evaluate the decline in the $\mathrm{SpO}_{2}$ at every 2 seconds by tracing the curve of $\mathrm{SpO}_{2}$, rather than to assess the simple subtraction of $\mathrm{SpO}_{2}$ between baseline and postexercise values. The aim of the present study was to first apply DDR to clinical research on COPD as an estimate of exercise capacity and then, to examine whether DDR is a potential parameter for manifold analysis of exercise capacity in patients with COPD. We measured the $\mathrm{SpO}_{2}$, not at every 2 seconds but rather, on a minute-by-minute basis because the measurements at every minute seem to minimize fine fluctuation in the $\mathrm{SpO}_{2}$ values and measurement errors, and to smooth the curve of temporal changes in $\mathrm{SpO}_{2}$ values for the assessment of overall changes in $\mathrm{SpO}_{2}$ values. In addition, the recordings at every minute seem to be more easily measured in clinical settings than those at every 2 seconds.

\section{Methods}

\section{Study subjects}

Subjects were randomly enrolled into the present study from a list of patients with COPD who had visited Osaka City University Respiratory Clinic. All subjects were $>40$ years of age. Subjects with concomitant confounding diseases, such as malignant disorders, cardiovascular abnormalities, or recent surgery, were excluded. No subjects had suffered from a recent respiratory tract infection or an exacerbation for at least 4 weeks prior to the study, or had clinical signs of heart failure. All subjects underwent physical examinations; anthropometric measurements, including body mass index (BMI); and assessment of lung function. BMI was calculated as body weight in kilograms divided by height in meters squared. The study was approved by the institutional review board of Osaka City University, and all subjects gave written informed consent. All procedures were done according to the research ethics of the Declaration of Helsinki. ${ }^{13}$

\section{Pulmonary function and 6MWT}

A spirometer (Chestac-8800; Chest Co., Tokyo, Japan) was used to obtain all baseline spirometric measurements (forced expiratory volume in 1 second $\left[\mathrm{FEV}_{1}\right]$, forced vital capacity [FVC], and $\mathrm{FEV}_{1} / \mathrm{FVC}$ ). COPD was diagnosed as stable airway obstruction with $\mathrm{FEV}_{1} / \mathrm{FVC}<70 \%$, according to the Global Initiative for Chronic Obstructive Lung Disease (GOLD) criteria. ${ }^{14}$ Diffusing capacity of the lung for carbon monoxide $\left(\mathrm{DL}_{\mathrm{CO}}\right)$ was measured by the single-breath carbon monoxide method, at least twice. No subjects received any medication during the 12 -hour period preceding the lung function test.

The 6MWT was performed indoors, along a flat, straight, $25 \mathrm{~m}$ walking course, according to international guidelines. ${ }^{10}$ Subjects were instructed to walk from end to end of the course and to cover as much distance as possible in the allotted period of 6 minutes. Subjective scores of dyspnea, using a modified version of the Borg scale, ${ }^{15,16}$ and $\mathrm{SpO}_{2}$ values, measured with pulse oximetry (PULSOX ${ }^{\circledR}-300$; Minolta Co., Tokyo, Japan) were obtained at every minute during the 6MWT. The modified version of the Borg scale consists of a vertical scale labeled 0 to 10 , with corresponding verbal expressions of the degree of breathlessness. Changes in $\mathrm{SpO}_{2}\left(\Delta \mathrm{SpO}_{2}\right)$ and those in Borg scale scores ( $\Delta$ Borg) during the $6 \mathrm{MWT}$ were calculated by subtracting the values at baseline from those immediately after walking for 6 minutes.

To calculate DDR, the "desaturation area" was first calculated as the total area above the curve created using $\mathrm{SpO}_{2}$ values observed at each minute during the $6 \mathrm{MWT}$, thereby summing up the difference between $\mathrm{SpO}_{2}$ of $100 \%$ and the patient's $\mathrm{SpO}_{2}$ at each minute (Figure 1). Next, DDR was obtained using the ratio of the desaturation area to 6MWD. Although the original version of the DDR was designed to record $\mathrm{SpO}_{2}$ values at every 2 seconds during the 6MWT, ${ }^{12}$ the values were measured at every minute in the present study. Subjects who walked shorter distances with higher overall quantity of desaturation presented with higher DDR values. 


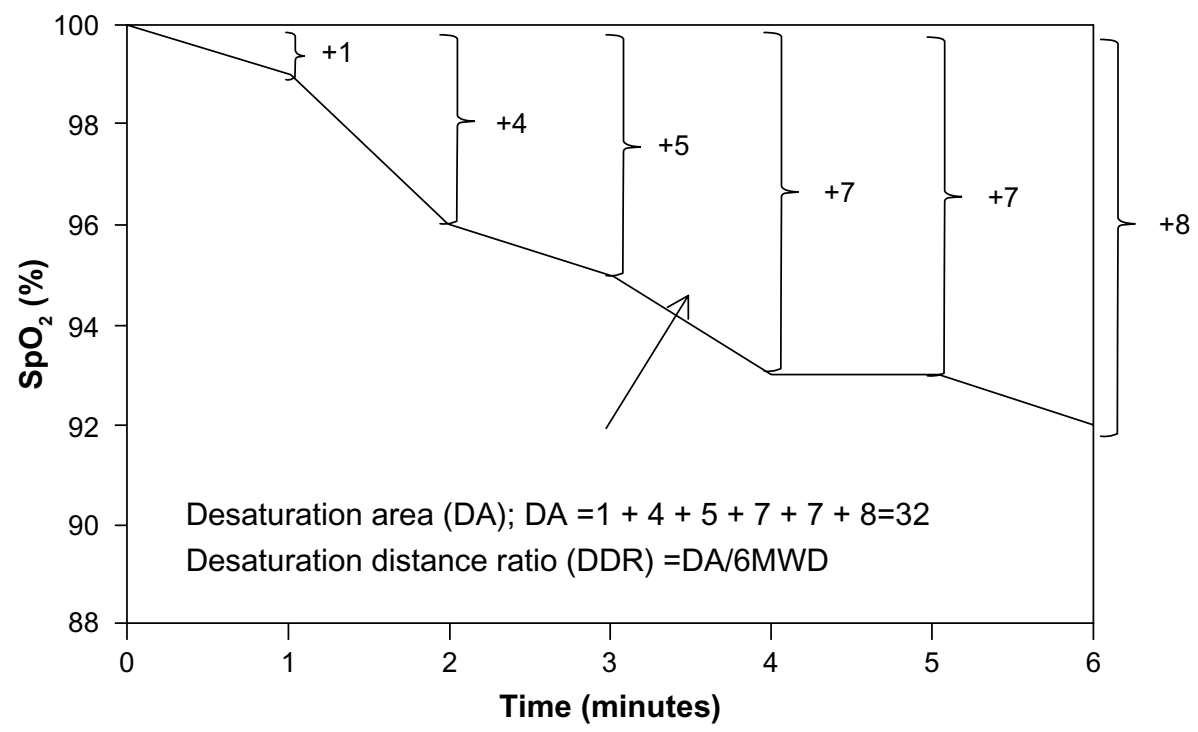

Figure I Desaturation distance ratio.

Notes: First, the desaturation area was calculated as the total area above the curve created using $\mathrm{SpO}_{2}$ values observed at each minute during the $6 \mathrm{MWT}$, thereby summing up the difference between $\mathrm{SpO}_{2}$ of $100 \%$ and the patient's $\mathrm{SpO}_{2}$ at each minute. Next, the DDR was obtained using the ratio of the desaturation area to the $6 \mathrm{MWD}$. Abbreviations: $6 \mathrm{MWD}$, 6-minute walk distance; $6 \mathrm{MWT}$, 6-minute walk test; $\mathrm{DA}$, desaturation area; DDR, desaturation distance ratio; $\mathrm{SpO}_{2}$, peripheral oxygen saturation.

\section{Statistical analysis}

All statistical analyses were performed using SPSS Statistics for Windows, Version 22.0.0.0 (IBM Corporation, Armonk, NY, USA). All data were presented as the median with the interquartile range and were analyzed nonparametrically. Correlations between study outcomes were assessed using Spearman's correlation coefficient. All $P$-values were two-tailed, and values less than 0.05 were considered statistically significant.

\section{Results}

\section{Subject characteristics}

A total 41 patients with COPD were enrolled into the study. Table 1 presents the background information of the subjects. All subjects were current smokers (50 [36-80] pack-years). Regular medication consisted of inhaled long-acting muscarinic antagonists $(n=32)$ and inhaled long-acting $\beta_{2}$-adrenergic receptor agonists $(n=30)$. Twenty subjects had received inhaled corticosteroids. No subjects had a baseline $\mathrm{SpO}_{2}$ less than $90 \%$ or received domiciliary oxygen therapy.

\section{Results of the 6MWT}

While 40 subjects completed 6 minutes of ambulation, one subject took a rest in the last minute without a drop in $\mathrm{SpO}_{2}$, mainly because of fatigue. The parameters obtained in the 6MWT are shown in Table 2. The 6MWD was 370 (328-445) m. Twentyfive subjects (61\%) had a $6 \mathrm{MWD} \geq 350 \mathrm{~m}$, while the remaining 16 subjects $(39 \%)$ had a $6 \mathrm{MWD}<350 \mathrm{~m}$. The decline in $\mathrm{SpO}_{2}$ values was $-5.0 \%(-8.0 \%$ to $-1.5 \%)$.

\section{Correlations of 6MWD and DDR with baseline pulmonary function parameters}

Significant correlations were observed between forced expiratory volume in 1 second $\left(\mathrm{FEV}_{1}\right)(\%$ predicted $)$ and two $6 \mathrm{MWT}$ parameters, that is, the 6MWD $(r=0.410, P=0.008)$ and DDR $(r=-0.658, P<0.001)$. Similarly, there were significant correlations of $\mathrm{FEV}_{1} / \mathrm{FVC}$ with the 6MWD $(r=0.370, P=0.017)$ and with the DDR $(r=-0.714, P<0.001)$. $\mathrm{DL}_{\mathrm{CO}}$ was significantly correlated with the 6MWD $(r=0.479, P=0.002)$ and DDR $(r=-0.470, P=0.002)$ (Table 3).

Table I Characteristics of subjects $(n=4 I)$

\begin{tabular}{|c|c|}
\hline Age (years) & 75 (68-79) \\
\hline Sex, male & $36(87.8 \%)$ \\
\hline BMI $\left(k g / m^{2}\right)$ & $22.3(19.4-23.8)$ \\
\hline Pack-years & $50(36-80)$ \\
\hline \multicolumn{2}{|l|}{ Medications } \\
\hline LABA & 30 (73.2\%) \\
\hline LAMA & $32(78.0 \%)$ \\
\hline ICS & $20(48.8 \%)$ \\
\hline FVC (\% predicted) & $101.6(88.5-120.4)$ \\
\hline FEV (\% predicted) & $54.8(39.8-77.6)$ \\
\hline $\mathrm{FEV}_{\mathrm{I}} / \mathrm{FVC}(\%)$ & $48.1(34.0-58.2)$ \\
\hline $\mathrm{DL}_{\mathrm{CO}}(\%$ predicted $)$ & $78.6(58.7-108.5)$ \\
\hline $\mathrm{SpO}_{2}$ at rest (\%) & $96.0(95.0-97.0)$ \\
\hline
\end{tabular}

Note: Data are presented as the median with the interquartile range, or number (\%). Abbreviations: $\mathrm{BMI}$, body mass index; $\mathrm{DL}_{\mathrm{CO}}$, diffusing capacity of the lung for carbon monoxide; $\mathrm{FEV}_{1}$, forced expiratory volume in I second; $\mathrm{FVC}$, forced vital capacity; ICS, inhaled corticosteroid; LABA, long-acting $\beta_{2}$ agonist; LAMA, long-acting muscarinic antagonist; $\mathrm{SpO}_{2}$, peripheral oxygen saturation. 
Table 2 6MWT parameters of subjects $(n=4 I)$

\begin{tabular}{ll}
\hline $6 \mathrm{MWD}(\mathrm{m})$ & $370(328$ to 445$)$ \\
Minimum $\mathrm{SpO}_{2}(\%)$ & $90.0(87.0$ to 93.0$)$ \\
$\Delta \mathrm{SpO}_{2}(\%)$ & $-5.0(-8.0$ to -1.5$)$ \\
$\Delta \mathrm{Borg}$ & $3.0(1.0$ to 4.8$)$ \\
\hline
\end{tabular}

Notes: Data are presented as the median with the interquartile range. $\Delta \mathrm{SpO}_{2}$ and $\Delta \mathrm{Borg}$ during the $6 \mathrm{MWT}$ were calculated by subtracting the values at baseline from those immediately after walking for 6 minutes. Borg refers to the modified Borg scale scores of subjective sense of dyspnea.

Abbreviations: $\triangle$ Borg, change in modified Borg scale scores; $\Delta \mathrm{SpO}_{2}$, change in $\mathrm{SpO}_{2}$ values; $6 \mathrm{MWD}$, 6-minute walk distance; $6 \mathrm{MWT}$, 6-minute walk test; $\mathrm{SpO}_{2}$, peripheral oxygen saturation.

\section{Correlations of 6MWD and DDR with changes in peripheral oxygenation and subjective sense of dyspnea}

During the $6 \mathrm{MWT}$, neither the $\Delta \mathrm{Borg}$ nor $\Delta \mathrm{SpO}_{2}$ was significantly correlated with the $6 \mathrm{MWD}$. In contrast, a significant correlation was observed between the DDR and $\Delta \mathrm{SpO}_{2}(r=-0.656$, $P<0.001$ ) (Figure 2). Of particular note is that the DDR correlated well with $\Delta$ Borg $(r=0.486, P=0.001)$ (Figure 3).

\section{Discussion}

It has been previously demonstrated that the 6MWD is associated with the following lung functions in COPD: the degree of airflow limitation as indicated by $\mathrm{FEV}_{1}$; the diffusing capacity of lung as indicated by $\mathrm{DL}_{\mathrm{CO}}$; and dynamic hyperinflation as assessed by inspiratory capacity during exercise. ${ }^{17-20}$ Thus, the 6MWD is considerably impacted by impaired lung function in patients with COPD. In the present study, we also found that the 6MWD was significantly correlated with the degree of airflow limitation and diffusing capacity of the lung in general in patients with COPD. In addition, for the first time, we demonstrated that DDR was also closely associated with impaired lung functions in patients with COPD, comparable to the close association of the 6MWD with impaired lung function.

Table 3 Correlations of 6MWD and DDR with baseline pulmonary function parameters $(n=4 I)$

\begin{tabular}{lll}
\hline & $\boldsymbol{r}$ & $\boldsymbol{P}$ \\
\hline 6MWD & & \\
$\mathrm{FEV}_{1}$ (\% predicted) & 0.410 & 0.008 \\
$\mathrm{FEV}_{1} / \mathrm{FVC}$ & 0.370 & 0.017 \\
$\mathrm{DL}_{\mathrm{CO}}$ (\% predicted) & 0.479 & 0.002 \\
$\mathrm{DDR}$ & & \\
$\mathrm{FEV}$, (\% predicted) & -0.658 & $<0.001$ \\
$\mathrm{FEV}_{\text {/ } / F V C}$ & -0.714 & $<0.001$ \\
$\mathrm{DL}_{\mathrm{CO}}$ (\% predicted) & -0.470 & 0.002 \\
\hline
\end{tabular}

Note: Spearman's correlation analyses were used to evaluate the association of 6MWD and DDR with baseline pulmonary function parameters.

Abbreviations: 6MWD, 6-minute walk distance; DDR, desaturation distance ratio; $\mathrm{DL}_{\mathrm{co}}$, diffusing capacity of the lung for carbon monoxide; $\mathrm{FEV}_{1}$, forced expiratory volume in I second; FVC, forced vital capacity.
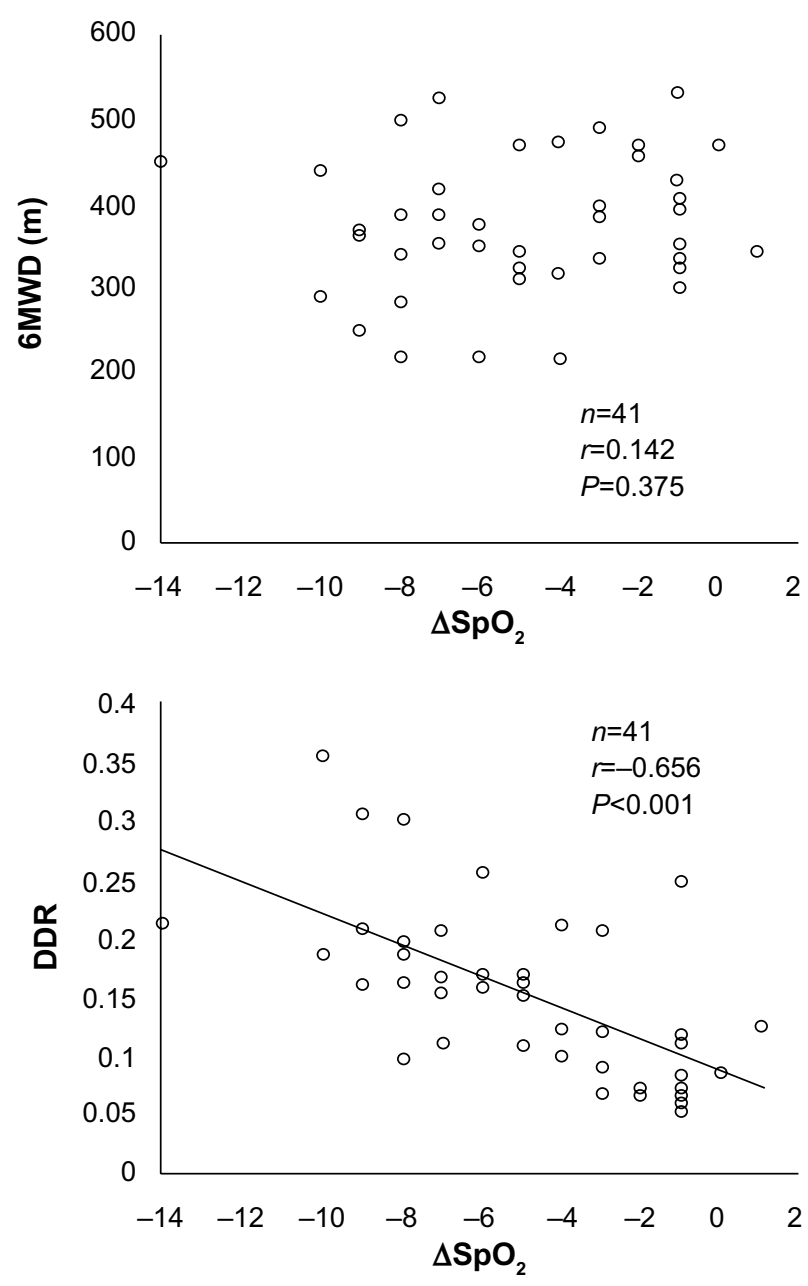

Figure 2 Correlation of $\triangle \mathrm{SpO}_{2}$ with 6MWD and DDR.

Notes: $\Delta \mathrm{SPO}_{2}$ was calculated by subtracting the values at baseline from those immediately after walking for 6 minutes. Spearman's correlation coefficients and $P$-values are shown.

Abbreviations: $\Delta \mathrm{SpO}_{2}$, change in $\mathrm{SpO}_{2}$ values; 6MWD, 6-minute walk distance; $\mathrm{DDR}$, desaturation distance ratio; $\mathrm{SpO}_{2}$, peripheral oxygen saturation.

The novel finding of this study is that the DDR was significantly correlated with the reduction in $\mathrm{SpO}_{2}$ during the $6 \mathrm{MWT}$. In contrast, we also found that the reduction in $\mathrm{SpO}_{2}$ was not significantly correlated with the 6MWD, which is consistent with the findings of a previous study. ${ }^{21}$ The 6MWT includes two objective parameters: walk distance (6MWD) and oxygen saturation $\left(\mathrm{SpO}_{2}\right)$. It is important to examine the deterioration of exercise capacity due to the functional abnormalities of extrapulmonary systems, since COPD is characterized by various comorbidities, including cardiovascular and metabolic abnormalities, affecting oxygen delivery and consumption in peripheral muscles. Therefore, reductions in $\mathrm{SpO}_{2}$ during the 6MWT also indicate the impact of these comorbidities in COPD. Accordingly, it is likely that the 6MWD does not provide specific information on multiple comorbidities in COPD. In other words, the 

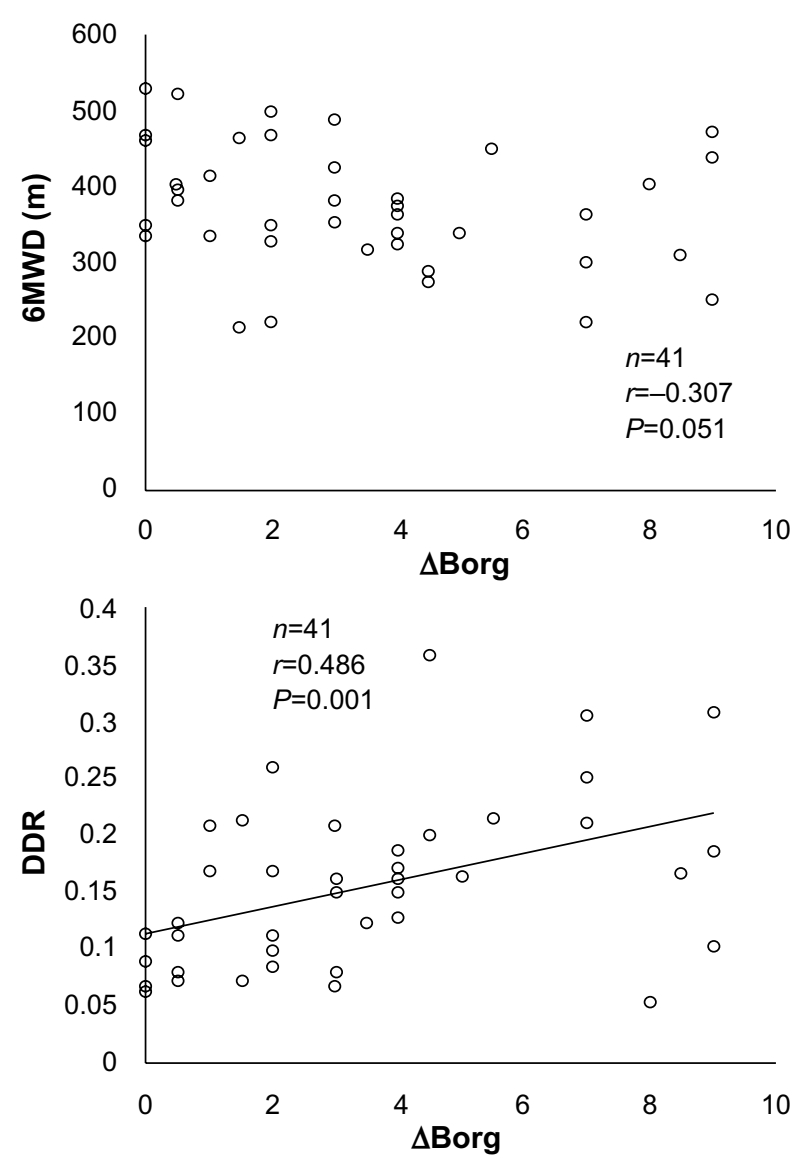

Figure 3 Correlation of $\triangle B$ org with $6 M W D$ and DDR.

Notes: $\triangle$ Borg during the $6 \mathrm{MWT}$ was calculated by subtracting the values at baseline from those immediately after walking for 6 minutes. Spearman's correlation coefficients and $P$-values are shown. Borg refers to the modified Borg scale scores of subjective sense of dyspnea.

Abbreviations: $\triangle$ Borg, change in modified Borg scale scores; 6MWD, 6-minute walk distance; 6MWT, 6-minute walk test; DDR, desaturation distance ratio.

$6 \mathrm{MWD}$ is affected to some degree by mechanical defects of the pulmonary system in patients with COPD. Given that systemic oxygen deficits play a major role in exercise limitations, some novel parameters incorporating exercise-induced oxygen desaturation with walk distance are desirable. The DDR appears to satisfy this requirement.

Another subjective parameter in the 6WMT is the dyspnea index of the perceived exertion scale (Borg scale). Intriguingly, the DDR was also correlated with the subjective dyspnea index during the $6 \mathrm{MWT}$, as assessed by changes in the Borg scale. In general, it is known that self-reported dyspnea, as measured by the Borg scale, during exercise is often poorly-reproducible. ${ }^{22}$ In addition, because of the complexity of the disturbances in systemic mechanisms during exercise in COPD, it is difficult to identify which primary factors contribute to the sensation of dyspnea. ${ }^{23,24}$ In this sense, the present finding raises the possibility that the DDR might reflect the subjective dyspnea index due to multifactorial systemic mechanisms and that DDR might have an advantage in the assessment of daily activities, not only through physiological mechanics but also through the subjective sense of dyspnea on exertion. It is reported that exercise capacity assessed by submaximal exercise tests like the 6MWT is a strong determinant of daily physical activity. ${ }^{25}$ Decreases in exercise capacity and those in physical activity are associated with higher mortality. ${ }^{4,26}$ A previous study demonstrated that the desaturation area represented by total area above the curve created using $\mathrm{SpO}_{2}$ values observed at each minute during the 6MWT was associated with mortality in patients with idiopathic pulmonary fibrosis. ${ }^{27}$ The association of DDR with the amount of physical activity in daily life and mortality in patients with COPD should also be examined. Moreover, considering both energy expenditure and oxygen desaturation, it is noteworthy to examine aerobic metabolism during the 6MWT. A decline in oxygen saturation partly reflects an increase in oxygen consumption accompanied by aerobic metabolism, as well as a decrease in oxygen intake through the lung during exercise. Energy expenditure during exercise might originate, not only from aerobic but also, from anaerobic metabolism. Based on the DDR, some new parameters should be developed to investigate the degree of aerobic and anaerobic metabolism during exercise.

Our study has some limitations. First, a small number of subjects were recruited, possibly resulting in a lack of sufficient statistical power. A large population study including ex-smokers will be necessary to confirm the present results. Second, most of the study subjects were males (87.8\%). Females have lower exercise capacity than males ${ }^{28}$ and seem to be more prone to impaired muscle function, ${ }^{29}$ thus the subject sex bias might have affected the present findings regarding the DDR. Lastly, it is necessary to perform the present testing in patients with COPD who need oxygen supplementation and to examine whether the trajectory of $\mathrm{SpO}_{2}$ values during the 6MWT with oxygen supplementation in these patients is similar to that in patients who do not need oxygen supplementation. Furthermore, it seems worthwhile to examine whether oxygen supplementation simply raises the overall level of $\mathrm{SpO}_{2}$ or modifies the shape of the trajectory of $\mathrm{SpO}_{2}$ values in these patients.

In conclusion, the DDR as well as the 6MWD during the 6MWT correlated well with baseline $\mathrm{FEV}_{1}$ and $\mathrm{DL}_{\mathrm{CO}}$ in patients with COPD. In addition, the DDR is more informative to evaluate the exercise capacity associated with oxygen desaturation and the subsequent sense of dyspnea with exercise in patients with COPD. The impact of the parameter on physical activity and mortality can and should be investigated 
in patients with COPD. Furthermore, it would be helpful to suggest further practical implications of these findings for practitioners in pulmonary rehabilitation.

\section{Acknowledgment}

The authors thank Forte Science Communications for editorial help with the manuscript.

\section{Disclosure}

The authors report no conflicts of interest in this work.

\section{References}

1. Lopez AD, Murray CC. The global burden of disease, 1990-2020. Nat Med. 1998;4(11):1241-1243.

2. Miravitlles M. Cough and sputum production as risk factors for poor outcomes in patients with COPD. Respir Med. 2011;105(8): $1118-1128$.

3. Jones P, Miravitlles M, van der Molen T, Kulich K. Beyond $\mathrm{FEV}_{1}$ in COPD: a review of patient-reported outcomes and their measurement. Int J Chron Obstruct Pulmon Dis. 2012;7:697-709.

4. Waschki B, Kirsten A, Holz O, et al. Physical activity is the strongest predictor of all-cause mortality in patients with COPD: a prospective cohort study. Chest. 2011;140(2):331-342.

5. O'Donnell DE, Gebke KB. Activity restriction in mild COPD: a challenging clinical problem. Int J Chron Obstruct Pulmon Dis. 2014;9:577-588.

6. Butland RJ, Pang J, Gross ER, Woodcock AA, Geddes DM. Two-, six-, and 12-minute walking tests in respiratory disease. $\mathrm{Br} \mathrm{Med} \mathrm{J} \mathrm{(Clin} \mathrm{Res}$ $E d)$. 1982;284(6329):1607-1608.

7. Guyatt GH, Sullivan MJ, Thompson PJ, et al. The 6-minute walk: a new measure of exercise capacity in patients with chronic heart failure. Can Med Assoc J. 1985;132(8):919-923.

8. Poole-Wilson PA. The 6-minute walk. A simple test with clinical application. Eur Heart J. 2000;21(7):507-508.

9. Solway S, Brooks D, Lacasse Y, Thomas S. A qualitative systematic overview of the measurement properties of functional walk tests used in the cardiorespiratory domain. Chest. 2001;119(1):256-270.

10. ATS Committee on Proficiency Standards for Clinical Pulmonary Function Laboratories. ATS statement: guidelines for the six-minute walk test. Am J Respir Crit Care Med. 2002;166(1):111-117.

11. Casanova C, de Torres JP, Aguirre-Jaíme A, et al. The progression of chronic obstructive pulmonary disease is heterogeneous: the experience of the BODE cohort. Am J Respir Crit Care Med. 2011;184(9): $1015-1021$

12. Pimenta SP, Rocha RB, Baldi BG, Kawassaki Ade M, Kairalla RA, Carvalho CR. Desaturation - distance ratio: a new concept for a functional assessment of interstitial lung diseases. Clinics (Sao Paulo). 2010;65(9):841-846.

13. World Medical Association. World Medical Association Declaration of Helsinki: Ethical principles for medical research involving human subjects. JAMA. 2013;310(20):2191-2194.
14. Global Initiative for Chronic Obstructive Lung Disease (GOLD). Global Strategy for the Diagnosis, Management, and Prevention of Chronic Obstructive Pulmonary Disease. Vancouver, WA: GOLD; 2013. Available from: http://www.goldcopd.org/uploads/users/files/GOLD_ Report_2013_Feb20.pdf. Accessed June 25, 2014.

15. Burdon JG, Juniper EF, Killian KJ, Hargreave FE, Campbell EJ. The perception of breathlessness in asthma. Am Rev Respir Dis. 1982;126(5):825-828.

16. Hareendran A, Leidy NK, Monz BU, Winnette R, Becker K, Mahler DA. Proposing a standardized method for evaluating patient report of the intensity of dyspnea during exercise testing in COPD. Int $J$ Chron Obstruct Pulmon Dis. 2012;7:345-355.

17. Wijkstra PJ, TenVergert EM, van der Mark TW, et al. Relation of lung function, maximal inspiratory pressure, dyspnoea, and quality of life with exercise capacity in patients with chronic obstructive pulmonary disease. Thorax. 1994;49(5):468-472.

18. Andrianopoulos V, Franssen FM, Peeters JP, et al. Exercise-induced oxygen desaturation in COPD patients without resting hypoxemia. Respir Physiol Neurobiol. 2014;190:40-46.

19. Carter R, Holiday DB, Nwasuruba C, Stocks J, Grothues C, Tiep B. 6-minute walk work for assessment of functional capacity in patients with COPD. Chest. 2003;123(5):1408-1415.

20. Marin JM, Carrizo SJ, Gascon M, Sanchez A, Gallego B, Celli BR. Inspiratory capacity, dynamic hyperinflation, breathlessness, and exercise performance during the 6-minute-walk test in chronic obstructive pulmonary disease. Am J Respir Crit Care Med. 2001;163(6): 1395-1399.

21. Mak VH, Bugler JR, Roberts CM, Spiro SG. Effect of arterial oxygen desaturation on six minute walk distance, perceived effort, and perceived breathlessness in patients with airflow limitation. Thorax. 1993;48(1):33-38.

22. Belman MJ, Brooks LR, Ross DJ, Mohsenifar Z. Variability of breathlessness measurement in patients with chronic obstructive pulmonary disease. Chest. 1991;99(3):566-571.

23. American Thoracic Society. Dyspnea. Mechanisms, assessment, and management: a consensus statement. Am J Respir Crit Care Med. 1999;159(1):321-340.

24. Grazzini M, Stendardi L, Gigliotti F, Scano G. Pathophysiology of exercise dyspnea in healthy subjects and in patients with chronic obstructive pulmonary disease (COPD). Respir Med. 2005;99(11):1403-1412.

25. Pitta F, Troosters T, Spruit MA, Probst VS, Decramer M, Gosselink R. Characteristics of physical activities in daily life in chronic obstructive pulmonary disease. Am J Respir Crit Care Med. 2005;171(9):972-977.

26. Casanova C, Cote CG, Marin JM, et al. The 6-min walking distance: long-term follow up in patients with COPD. Eur Respir J. 2007;29(3):535-540.

27. Flaherty KR, Andrei AC, Murray S, et al. Idiopathic pulmonary fibrosis: prognostic value of changes in physiology and six-minute-walk test. Am J Respir Crit Care Med. 2006;174(7):803-809.

28. de Torres JP, Casanova C, Hernández C, Abreu J, Aguirre-Jaime A, Celli BR. Gender and COPD in patients attending a pulmonary clinic. Chest. 2005;128(4):2012-2016.

29. Janaudis-Ferreira T, Wadell K, Sundelin G, Lindström B. Thigh muscle strength and endurance in patients with COPD compared with healthy controls. Respir Med. 2006;100(8):1451-1457.
International Journal of COPD

\section{Publish your work in this journal}

The International Journal of COPD is an international, peer-reviewed journal of therapeutics and pharmacology focusing on concise rapid reporting of clinical studies and reviews in COPD. Special focus is given to the pathophysiological processes underlying the disease, intervention programs, patient focused education, and self management protocols.

\section{Dovepress}

This journal is indexed on PubMed Central, MedLine and CAS. The manuscript management system is completely online and includes a very quick and fair peer-review system, which is all easy to use. Visit http://www.dovepress.com/testimonials.php to read real quotes from published authors. 